\title{
Nonlinear oscillations of a sandwich plate with a 3D-printed honeycomb core
}

\author{
${ }^{1}$ A. Pidgorny Institute of M echanical Engineering Problems \\ of the National Academy of Sciences of U kraine \\ 2/10 Pozharsky St., Kharkiv 61046, Ukraine; e-mail: admi@ ipmach.kharkov.ua \\ ${ }^{2}$ National Technical U niversity "K harkiv Polytechnic Institute" \\ 2 Kyrpychova St., Kharkiv 61002, U kraine; e-mail: omsroot@ kpi.kharkov.ua

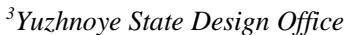 \\ 3 K ryvorizka St., D nipro 49008, Ukraine; e-mail: info@ yuzhnoye.com
}

\begin{abstract}
A three-layer sandwich plate with a FDM-printed honeycomb core made of polycarbonate is considered. The upper and lower faces of the sandwich are made of a carbon fiber-reinforced composite. To study the response of the sandwich plate, the honeycomb core is replaced with a homogeneous layer with appropriate mechanical properties. To verify the honeycomb core model, a finite-element simulation of the representative volume of the core was performed using the ANSYS software package. A modification of the high-order shear theory is used to describe the structure dynamics. The assumed-mode method is used to simulate nonlinear forced oscillations of the plate. The Rayleigh-Ritz method is used to calculate the eigenfrequencies and eigenmodes of the plate, in which the displacement of the plate points during nonlinear oscillations are expanded. This technique allows one to obtain a finite-degree-of-freedom nonlinear dynamic system, which describes the oscillations of the plate. The frequency response of the system is calculated using the continuation approach applied to a two-point boundary value problem for nonlinear ordinary differential equations and the Floquet multiplier method, which allows one to determine the stability and bifurcations of periodic solutions. The resonance behavior of the system is analyzed using its frequency response.

The proposed technique is used to analyze the forced oscillations of a square three-layer plate clamped along the contour. The results of the analysis of the free oscillations of the plate are compared with those of ANSYS finiteelement simulation, and the convergence of the results with increasing number of basis functions is analyzed. The comparison shows that the results are in close agreement. The analysis of the forced oscillations shows that the plate executes essentially nonlinear oscillations with two saddle-node bifurcations in the frequency response curve, in which the periodic motion stability of the system changes. The nonlinear oscillations of the plate near the first fundamental resonance are mostly monoharmonic. They may be calculated using the describing function method.
\end{abstract}

Keywords sandwich plate, honeycomb core, homogenization, nonlinear dynamic system, frequency response.

1. Wilkins D. J., Bert C. W., Egle D. M. Free vibrations of orthotropic sandwich conical shells with various boundary conditions. Journal of Sound and Vibration. 1970. V. 13. Pp. 211-228.

https://doi.org/10.1016/S0022-460X(70)81175-0

\author{
2. Kanematsu H. H., Hirano Y. Bending and vibration of CFRP - faced rectangular \\ sandwich plates. Composite Structures. 1988. V, 10. Pp. 145-163. \\ https://doi.org/10.1016/0263-8223(88)90044-X
}

\section{Lee L. J., Fan Y. J. Bending and vibration analysis of composite sandwich plates. Composite Structures. 1996. V. 60. Pp. 103-112. \\ https://doi.org/10.1016/0045-7949(95)00357-6}


4. Frostig Y., Baruch M., Vilnay O., Sheinman I. High-oder theory for sandwich beam with transversely flexible core. ASCE Journal of Engineering Mechanics. 1992. V. 118. No. 5. Pp. 1026-1043.

https://doi.org/10.1061/(ASCE)0733-9399(1992)118:5(1026)

5. Frostig Y., Thomsen O. T. High-order free vibration of sandwich panels with a flexible core. International Journal of Solids and Structures. 2004. V. 41. Pp. 16971724.

https://doi.org/10.1016/j.ijsolstr.2003.09.051

6. Frostig Y., Thomsen O. T. On the free vibration of sandwich panels with a transversely flexible and temperature-dependent core material - Part I:

Mathematical formulation. Composites Science and Technology. 2009. V. 69. Pp. 856-862.

https://doi.org/10.1016/j.compscitech.2008.03.003

7. Yu S. D., Cleghorn W. L. Free flexural vibration analysis of symmetric honeycomb panels. Journal of Sound and Vibration. 2005. V. 284. Pp. 189-204. https://doi.org/10.1016/j.jsv.2004.06.028

8. Malekzadeh K., Khalili M. R., Mittal R. K. Local and global damped vibrations of plates with a viscoelastic soft flexible core: An improved high-order approach. Journal of Sandwich Structures and Materials. 2005. V. 7. Pp. 431-456. https://doi.org/10.1177/1099636205053748

9. Yongqiang L., Zhiqiang J. Free flexural vibration analysis of symmetric rectangular honeycomb panels with SCSC edge supports. Composite Structures. 2008. V. 83. Pp. 154-158.

https://doi.org/10.1016/j.compstruct.2007.04.004

10. Kheirikhah M. M., Khalili S. M. R., Fard K. M. Biaxial buckling analysis of softcore composite sandwich plates using improved high-order theory. European Journal of Mechanics A/Solids. 2012. V. 31. Pp. 54-66.

https://doi.org/10.1016/j.euromechsol.2011.07.003

11. Ramian A., Jafari-Talookolaei R.-A., Valvo P. S., Abedi M. Free vibration analysis of sandwich plates with compressible core in contact with fluid. ThinWalled Structures. 2020. V. 157. Paper no. 107088.

https://doi.org/10.1016/j.tws.2020.107088 
12. Li Y., Yao W., Wang T. Free flexural vibration of thin-walled honeycomb sandwich cylindrical shells. Thin-Walled Structures. 2020. V. 157. Paper no. 107032.

https://doi.org/10.1016/j.tws.2020.107032

13. Hudramovich V. S., Demenkov A. F. Elastoplastic Structures with Shape Imperfections and Residual Stresses. Kyiv: Naukova Dumka, 1991. 176 pp. (in Russian).

14. Hudramovich V. S., Skalskyi V. R., Selivanov Yu. M. Holographic and Acoustic-Emissive Diagnostics of Structures and Materials. Z. T. Nazarchiuk (Ed.). Lviv: Prostir-M, 2017. 492 pp. (in Ukrainian).

15. Hudramovich V. S. Strength, reliability, and life of aerospace and power engineering structures. Teh. Mrh. 2021. No. 2. Pp. 100-106. (in Ukrainian). https://doi.org/10.15407/itm2021.02.100

16. Catapano A., Montemurro M. A multi-scale approach for the optimum design of sandwich plates with honeycomb core. Part I: homogenisation of core properties. Composite Structures. 2014. V. 118. Pp. 664-676.

https://doi.org/10.1016/j.compstruct.2014.07.057

17. Grediac M. A finite element study of the transverse hear in honeycomb cores. International Journal of Solids and Structures. 1993. V. 30. No. 13. Pp. 17771788.

https://doi.org/10.1016/0020-7683(93)90233-W

18. Jones R. M. Mechanics of Composite Materials. CRC Press, 1998. 538 pp.

19. Ramian A., Jafari-Talookolaei R.-A., Valvo P. S., Abedi M. Free vibration analysis of sandwich plates with compressible core in contact with fluid. ThinWalled Structures. 2020. V. 157. Paper no. 107088 https://doi.org/10.1016/j.tws.2020.107088

20. Reddy J. N. A simple higher-order theory for laminated composite plates. ASME Journal of Applied Mechanics. 1984. V. 51. Pp. 745-752.

https://doi.org/10.1115/1.3167719

21. Reddy J. N. A refined nonlinear theory of plates with transverse shear 
deformation. International Journal of Solids and Structures. 1984. V. 20. No. 9/10.

Pp. 881-896.

https://doi.org/10.1016/0020-7683(84)90056-8

22. Novozhilov V. V. Foundations of the Nonlinear Theory of Elasticity. Moscow: OGIZ, 1948. 211 pp. (in Russian).

23. Meirovitch L. Elements of Vibration Analysis. New York: McGraw-Hill, 1998. $560 \mathrm{pp}$.

24. Chernobryvko M. V., Avramov K. V., Romanenko V. N., Batutina T. J., Tonkonogenko A. M. Free linear vibrations of thin axisymmetric parabolic shells. Meccanica. 2014. V. 49. No. 12. Pp. 2839-2845.

https://doi.org/10.1007/s11012-014-0027-6

25. Parker T. S., Chua L. O. Practical numerical algorithms for chaotic systems. New York: Springer-Verlag. 1989. 348 pp.

https://doi.org/10.1007/978-1-4612-3486-9

26. Seydel R. Tutorial on continuation. International Journal of Bifurcation and Chaos. 1991. V. 1. Pp. 3-11.

https://doi.org/10.1142/S0218127491000026

27. Seydel R. Nonlinear computation. International Journal of Bifurcation and Chaos. 1997. V. 7. Pp. 2105-2126.

https://doi.org/10.1142/S0218127497001564

28. Avramov K., Raimberdiyev T. Bifurcations behavior of bending vibrations of beams with two breathing cracks. Engineering Fracture Mechanics. 2017. V. 178.

Pp. 22-38

https://doi.org/10.1016/j.engfracmech.2017.04.006

29. Hohe J., Becker W. Effective stress-strain relations for two-dimensional cellular sandwich cores: Homogenization, material models, and properties. Applied Mechanics Reviewer. 2002. V. 5. No. 1. Pp. 61-87. https://doi.org/10.1115/1.1425394

30. Burton W. S., Noor A. K. Assessment of continuum models for sandwich panel honeycomb cores. Computer Methods in Applied Mechanics and Engineering. 1997. V. 145. Pp. 341-360. 
31. Avramov K. Bifurcations of parametric oscillations of beams with three equilibrium. Acta Mechanica. 2003. V. 164. Pp. 115-138.

https://doi.org/10.1007/s00707-003-0022-9

32. Avramov K. Nonlinear beam oscillations excited by lateral force at combination resonance. Journal of Sound and Vibration. 2002. V. 257. Pp. 337-359.

https://doi.org/10.1006/jsvi.2002.5043

33. Amabili M. Nonlinear Vibrations and Stability of Shells and Plates. New York: Cambridge University Press,. 2008. 390 pp.

https://doi.org/10.1017/CBO9780511619694

Received on April 21, 2021,

in final form on November 24, 2021 